\title{
The influencing factors of gas-oil ratio in production were studied by numerical simulation method
}

\author{
Liang Hongyan ${ }^{1}$ \\ ${ }^{1}$ Research Institute of Exploration and Development of Daqing Oilfield Co. Ltd,Daqing, Heilongjiang, 163712
}

\begin{abstract}
In recent years, the gas-oil ratio of LaSaxing Oilfield has been on the rise and the variation characteristics of gas-oil ratio of each plant are quite different. The high production of gas leads to the intensification of three-phase interference of oil, gas and water, and the poor fluidity of crude oil after degassing, which affects the overall development effect of the oilfield.Though the method of oil and gas water three phase numerical simulation, the conceptual model was established. Based on the model, analysing the change of producing gas-oil ratio by designing the scheme of numerical simulation under different factors points out the results_ _ the formation pressure is the key factors influenced the producing gas-oil ratio change and the formation pressure level determines the trend of the producing gas-oil ratio. The results provide a technical support for oilfield production safety and the optimization of the ground production system, and achieve an important practical significance for oilfield sustainable development.
\end{abstract}

\section{Preface}

With the continuously deepen demodex SaXing oilfield development level and the change of the pattern, the profound changes, underground stress field and fluid field in oilfield development regularity and main technical parameters compared with previous had obvious changes, the relationship of oil and gas also will change, each block producing gas-oil ratio is on the rise and GeChang producing gas-oil ratio variation characteristics differences between larger, high volume in oil, gas, water phase interference, degassing after crude oil mobility, affect oilfield development effect as a whole. Though the method of oil and gas water three phase numerical simulation, the conceptual model was established. Based on the model, designing 32 numerical simulation program with different parameters, including reservoir condition, crude oil viscosity, formation pressure, low pressure and well pattern well spacing. Then under the main factors influenced the producing gas-oil ratio change analysing, points out that the formation pressure is the key factors influencing the producing gas-oil ratio change and the formation pressure level determines the trend of the producing gas-oil ratio.

\section{Establishment of numerical simulation model}

An ideal numerical simulation model was established by using the three-phase numerical simulation method of oil, gas and water. Considering the solubility of gas in crude oil and water, 32 sets of numerical simulation schemes were designed to study the influence of water cut and formation pressure changes on the gas-oil ratio. In consideration of reservoir properties, well pattern and well spacing, the influence of gas-oil ratio on crude oil viscosity under water drive condition is determined.

The basic situation of the model is: 20 small layers vertically, the permeability gradually increases from top to bottom, and the well pattern with 250 meters five-point method area is adopted, with 9 injections and 16 production. The grid number is $110 \times 110 \times 20$, the mesh step length is 20 meters, and the well network is 250 meters well spacing by five-point method.

Table 1 basic parameters model

\begin{tabular}{|c|c|c|c|c|}
\hline \multicolumn{3}{|c|}{ Permeability } & Porosity & $\begin{array}{c}\text { Effective } \\
\text { thickness }\end{array}$ \\
\hline PERMX & PERMY & PERMZ & PORO & DZNET \\
\hline $7 * 5$ & $7 * 5$ & $0.7 * 5$ & $0.05 * 5$ & $0.0118 * 5$ \\
\hline $47 * 6$ & $47 * 6$ & $4.7 * 6$ & $0.12 * 6$ & $0.25 * 6$ \\
\hline $82 * 2$ & $82 * 2$ & $8.2 * 2$ & $0.18 * 2$ & $0.47 * 2$ \\
\hline $227 * 7$ & $227 * 7$ & $22.7 * 7$ & $0.2 * 7$ & $0.73 * 7$ \\
\hline
\end{tabular}
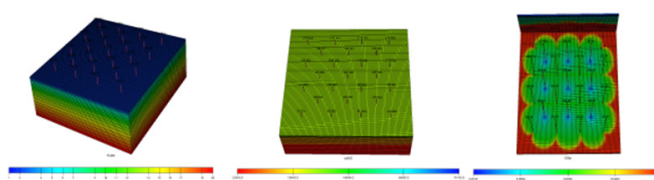

Fig. 1Model permeability and saturation distribution 


\section{Simulation results and analysis}

\subsection{Numerical simulation of different permeability}

The single-layer homogeneous conceptual model was established, and the reservoir thickness was $0.73 \mathrm{~m}$. Porosity 0.24 ; Oil saturation $0.63 \sim 0.81$; The viscosity of crude oil is 6MPa.s; Dissolved gas-oil ratio $46.7 \mathrm{~m} 3$ / ton; Five point method area well pattern, well spacing $250 \mathrm{~m}, 9$ injection 16 production; Formation pressure 9.5MPa, saturation pressure 9.42MPa, flow pressure $7 \mathrm{MPa}$. Grid number: $110^{*} 110 * 1$; Three schemes with designed permeability of $50 \mathrm{mD}(\mathrm{H} 1), 300 \mathrm{mD}(\mathrm{H} 2)$ and $800 \mathrm{mD}(\mathrm{H} 3)$ respectively showed stable changes in gas-oil ratio (Fig. 2).
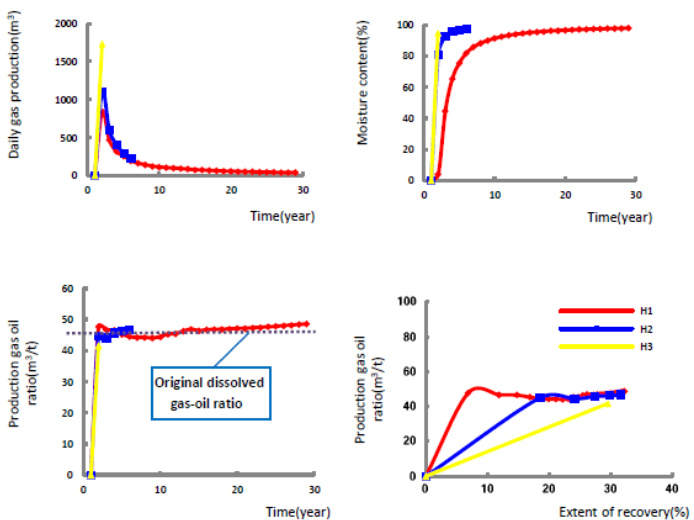

Fig. 2 Numerical simulation results of different permeability

\subsection{Numerical simulation of different crude oil viscosities}

A multi-layer heterogeneous conceptual model with 20 layers was established. The reservoir thickness is $0.118 \sim$ $0.73 \mathrm{~m}$; Porosity $0.05 \sim 0.2$; Permeability of $7 \sim 227 \mathrm{mD}$; Oil saturation $0.47 \sim 0.89$; Dissolved gas-oil ratio $46.7 \mathrm{~m} 3$ / ton; Five point method area well pattern, well spacing 250m, 9 injection 16 production; Formation pressure $9.5 \mathrm{MPa}$, saturation pressure $9.42 \mathrm{MPa}$, flow pressure 7.4MPa; Grid number: $110 * 110 * 20$; The designed crude oil viscosity of 6MpA.s (D1), 9MpA.s (D2), 12MpA.s (D3), and 15MpA.s (D4) four sets of schemes, from the results, the production gas oil ratio change is basically stable (Fig. 3).
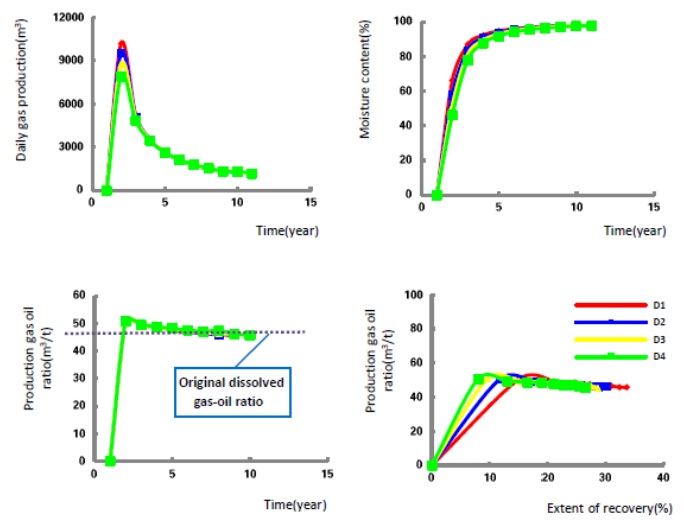

Fig. 3 Numerical simulation results of different oil viscosities

\subsection{Numerical simulation of different formation pressures}

A multi-layer heterogeneous conceptual model with 20 layers was established. The reservoir thickness is $0.118 \sim$ $0.73 \mathrm{~m}$; Porosity $0.05 \sim 0.2$; Permeability of $7 \sim 227 \mathrm{mD}$; Oil saturation $0.47 \sim 0.89$; The viscosity of crude oil is 7.8 $\sim 22.8 \mathrm{MPa}$. Dissolved gas-oil ratio $46.7 \mathrm{~m} 3$ / ton; Five point method area well pattern, well spacing $250 \mathrm{~m}, 9$ injection 16 production; Saturation pressure $9.42 \mathrm{MPa}$, flow pressure 7.4MPa; Grid number: $110 * 110 * 20$; Five plans with formation pressures of $7.5 \mathrm{MPa}(\mathrm{A} 1), 8.5 \mathrm{MPa}$ (A2), 9.5 MPa (A3), $10.5 \mathrm{MPa}$ (A4), and $11.5 \mathrm{MPa}$ (A5) were designed. The results show that the local formation pressure is below the saturation pressure, the initial degasser is obvious, and the gas-oil ratio of production is abnormally high. The gas-oil ratio was stable at other formation pressures (Fig. 4).
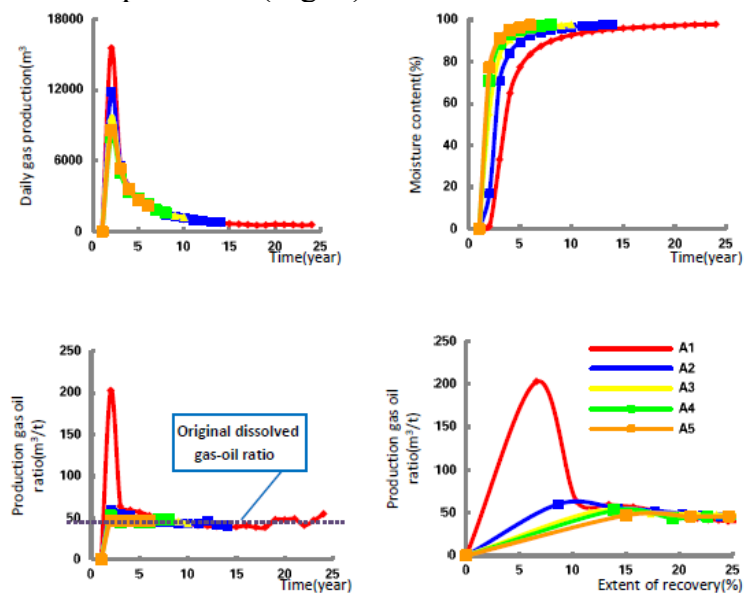

Fig. 4 Numerical simulation results for different formation pressures

\subsection{Numerical simulation of formation low pressure and different flow pressures}

A multi-layer heterogeneous conceptual model with 20 layers was established. The reservoir thickness is $0.118 \sim$ $0.73 \mathrm{~m}$; Porosity $0.05 \sim 0.2$; Permeability of $7 \sim 227 \mathrm{mD}$; Oil saturation $0.47 \sim 0.89$; The viscosity of crude oil is 7.8 $\sim 22.8 \mathrm{MPa}$. Dissolved gas-oil ratio $46.7 \mathrm{~m} 3$ / ton; Five point method area well pattern, well spacing $250 \mathrm{~m}, 9$ injection 16 production; Formation pressure $7.5 \mathrm{MPa}$; Saturation pressure 9.42MPa; Grid number: $110 * 110 * 20$; Six schemes were designed with flow pressures of $2 \mathrm{Mpa}$ (B1), 3Mpa (B2), 4Mpa (B3), 5Mpa (B4), 6Mpa (B5), and 7.4Mpa (B6). From the results, there were different degrees of degasser in the initial stage, and the gas-oil ratio of production increased, and then decreased gradually (Fig. $5)$.
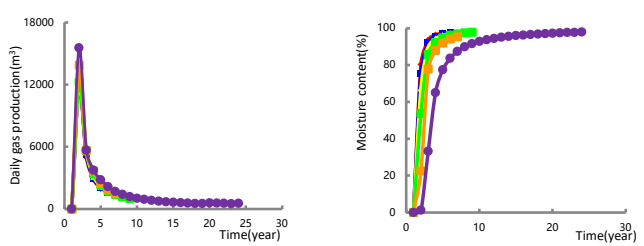

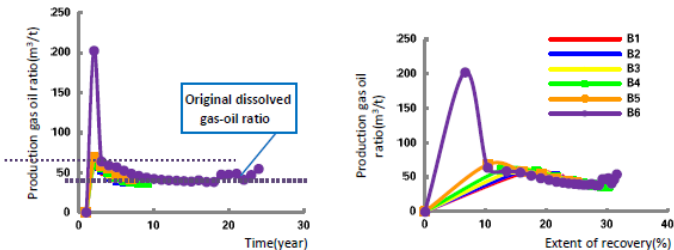

Fig. 5 Numerical simulation results of different flow pressures (formation low pressure)

\subsection{Numerical simulation of formation high pressure and different flow pressures}

A multi-layer heterogeneous conceptual model with 20 layers was established. The reservoir thickness is $0.118 \sim$ $0.73 \mathrm{~m}$; Porosity $0.05 \sim 0.2$; Permeability of $7 \sim 227 \mathrm{mD}$; Oil saturation $0.47 \sim 0.89$; The viscosity of crude oil is 7.8 $\sim 22.8 \mathrm{MPa}$. Dissolved gas-oil ratio $46.7 \mathrm{~m} 3$ / ton; Five point method area well pattern, well spacing $250 \mathrm{~m}, 9$ injection 16 production; Formation pressure $11.5 \mathrm{MPa}$; Saturation pressure 9.42MPa; Grid number: $110 * 110 * 20$; Six schemes with flow pressures of $2 \mathrm{Mpa}(\mathrm{C} 1), 3 \mathrm{Mpa}$ (C2), 4Mpa (C3), 5Mpa (C4), 6Mpa (C5) and 7.4Mpa (C6) were designed. From the results, the gas-oil ratio of production was basically stable (Fig. 6).
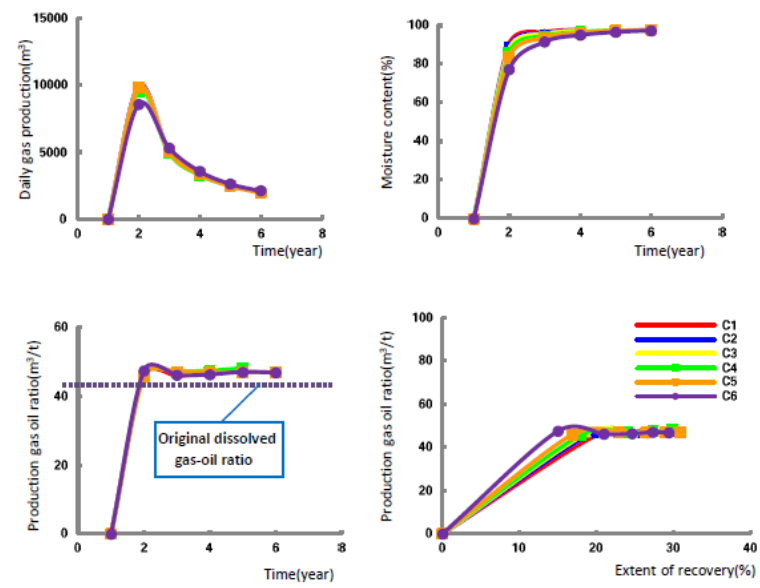

Fig. 6 Numerical simulation results of different flow pressures (formation high pressure)

\subsection{Numerical simulation of different well patterns and well spacing}

A multi-layer heterogeneous conceptual model with 20 layers was established. The reservoir thickness is $0.118 \sim$ $0.73 \mathrm{~m}$; Porosity $0.05 \sim 0.2$; Permeability of $7 \sim 227 \mathrm{mD}$; Oil saturation $0.47 \sim 0.89$; The viscosity of crude oil is 7.8 $22.8 \mathrm{MPa}$. Dissolved gas-oil ratio $46.7 \mathrm{~m} 3$ / ton; Formation pressure $11.5 \mathrm{MPa}$; Saturation pressure 9.42MPa; The flow pressure is $7 \mathrm{MPa}$; Grid number: $110 * 110 * 20$; Respectively set up five point $200 \mathrm{~m}$ spacing, 3035 (W2), five points $300 \mathrm{~m}$ spacing, 12 note 16 (W3), four point $100 \mathrm{~m}$ spacing, 84, $154(\mathrm{~S} 1)$, four point $200 \mathrm{~m}$ spacing, 21 note at four o 'clock 42 (S2), $300 \mathrm{~m}$ spacing, 1020 injection (S3), the nine point $100 \mathrm{~m}$ spacing, 63175 mining (J1), while $200 \mathrm{~m}$ spacing, 15 injection 48 production (J2), while $300 \mathrm{~m}$ spacing, 6 note $24(\mathrm{~J} 3)$ eight sets of solutions, from the point of the results, The gas-oil ratio of the inverse nine-point method with $300 \mathrm{~m}$ well spacing increased slightly, while the gas-oil ratio of the other method was basically stable (Fig. 7).
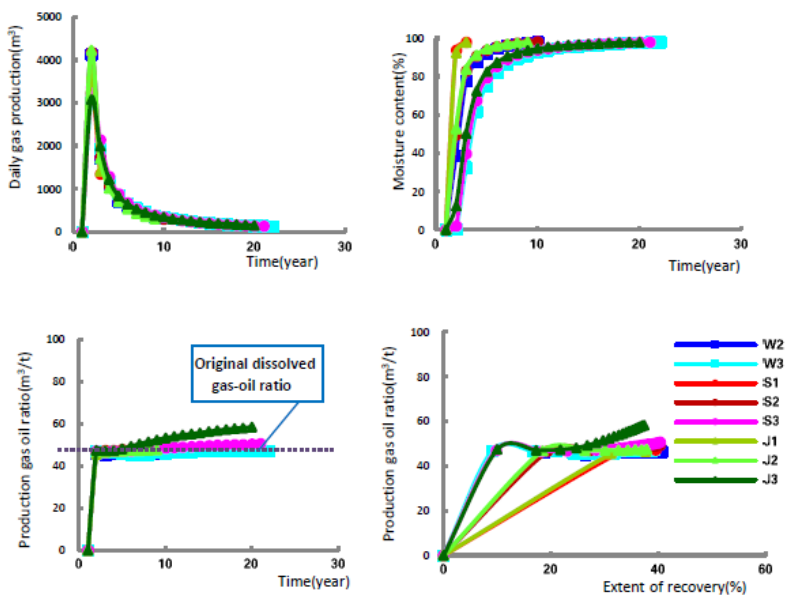

Fig. 7 Numerical simulation results of different well patterns and well spacing

\section{Conclusion:}

1. The formation pressure has a great influence on the change of gas-oil ratio. When the local pressure is lower than the saturation pressure, the gas-oil ratio increases rapidly. When the pressure is higher than saturation, the gas-oil ratio is basically stable. Under the formation high pressure, when the flow pressure is high, the gas-oil ratio is basically stable, and when the flow pressure is less than $3 \mathrm{MPa}$, the gas-oil ratio increases. Under the formation low pressure condition, the gas-oil ratio of production under different flow pressures is generally consistent.

2. Well pattern, well spacing, permeability and oil viscosity have no effect on the gas-oil ratio, and their values are consistent with the original dissolved gas-oil ratio.

3. Under the condition of 300-meter well spacing with the inverse nine-point method, the pressure does not stabilize and decreases due to the large water injection burden, leading to the obvious increase of gas-oil ratio. In ultra-high water cut period, in order to maintain formation pressure, the reverse nine point method needs to transfer.

\section{REFERENCES}

1. ZhaoYongsheng,ZhangShanyan\&ZhuNan.Changing Regularity of Production Gas Oil Ratio of La,Sa\&XingOilfields[J].PetroleumGeology\&Oil field Development in Daqing, 1998, 17(1): 22-25.

2. DING Fujun,WANG Pengtong,DING Wenlong. Research on Regularity of Gas Associated with Oilfields[J].Value Engineering,2018(13).

3. ZHANGJicheng,LI Qianru.Main Controlling Factors of Produced Gas/Oil Ratio in Water Flooding Fields[J].Contemporary Chemical Industry, 2016, 45(5): 935-939.

4. ZHANG Qiang,YU Hongfeng,BAI Yin,et al.Variation of Gas/Oil Ratio in east test area in 
Tazhong No.1 gas field, Tarim Basin[J].Xinjiang Petroleum Geology, 2011, 32(3): 285-287.

5. JIANG Yongping,TANG Renxuan.Analysis and recognition of high GOR production characteristics of reservoir for $\mathrm{CO} 2$ miscible displacement[J].Complex Reservoir, 2010, 3(2): 72-76. 